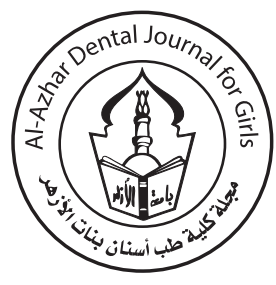

\title{
Response of Immature Permanent Teeth with Necrotic Pulp and Apical Periodontitis to Two Revascularization Protocols
}

\author{
Heba A. El kafy ${ }^{(1)}$, Mervat I. Fawzy ${ }^{(2)}$ and Hager A. Bastawy ${ }^{(3)}$
}

Codex : 01/1804

azhardentj@azhar.edu.eg

http://adjg.journals.ekb.eg

\section{KEYWORDS}

Revascularization, Chitosan,

$\mathrm{NaOCl}$, triple antibiotic paste.

\begin{abstract}
Aim: this study was to evaluate the response of immature permanent teeth with necrotic pulp and apical periodontitis to two revascularization protocols (Clinical study). Materials and Methods: Twenty upper central incisors with incompletely formed roots from young patients ( 7 to 18 years old) were selected according to the inclusion criteria. Patients were divided into two groups (10 roots each). Group I; irrigated with $1.5 \% \mathrm{NaOCl}$, disinfected using triple antibiotic paste mixed with propylene glycol as a vehicle and revascularization using blood clot. Group II; irrigated with $2 \%$ Chitosan, disinfected using triple antibiotic paste mixed with $2 \%$ Chitosan as a vehicle and revascularization using blood clot. Each experimental group were subdivided into 3 subgroups (A, B and C) according to the post treatment evaluation period 3,6 and 12 months respectively. Clinical and radiographic evaluation was performed in 3 follow up periods. Results: Clinical results revealed asymptomatic patient with presence of pulp response to hot sensitivity test in all patients of both groups (I, II) at 12 months follow up evaluation period. Radiographic results regarding increase in root length and resolution of apical radiolucency showed insignificant differences $(P>0.05)$ between the two experimental groups over the three follow-up evaluation periods $(3,6$ and12 months). Regarding increase in root thickness, in subgroups A, statistical analysis showed significant difference $(P \leq 0.05)$ between the experimental groups, on the other hand, the results were statistically insignificant $(P>0.05)$ in subgroups B and C (6 and 12 months) follow-up evaluation periods. Regarding decrease in apical diameter the results were statistically significant $(P \leq 0.05)$ over the three follow-up evaluation periods $(3,6,12$ months $)$.
\end{abstract}

\section{INTRODUCTION}

Trauma to the developing dentition, may results in pulp necrosis and incomplete root formation. Treatment of the young permanent tooth with

1. Assistant lecturer of Endodontics, Faculty of Dental Medicine for Girls, Al-Azhar University.

2. Professor of Endodontics, Endodontic Department, Faculty of Dental Medicine for Girls, AL-Azhar University.

3. Associate Professor of Endodontics, Endodontic Department, Faculty of Dental Medicine for Girls, AL-Azhar University 
necrotic pulp and an incompletely developed root is fraught with difficulty. Not only is the root canal system often difficult to fully debride, and obturat with blunderbuss apices, but the thin dentinal walls increase the risk of a subsequent fracture ${ }^{(1)}$.

Recently, revascularization procedures have been recommended to treat immature permanent teeth with necrotic pulp tissue and apical periodontitis. The treatment procedures have been shown to result in increased thickening of the canal walls by deposition of hard tissue and encourage continued root development ${ }^{(2)}$. To promote regeneration, the pulp space and dentinal walls must be sufficiently disinfected before performing pulp regeneration procedures. Therefore, researchers suggested that regenerative endodontic treatment will occur if it was possible to create an effectively disinfected canals and the coronal access was effectively sealed. The canals disinfection can be accomplished through irrigation and intracanal medicaments ${ }^{(3,4)}$. When considering the type of irrigants used for disinfection of the canal, it is important to balance the need to eliminate microorganisms with the need to maintain vitality of stem cells ${ }^{(5)}$. Sodium hypochlorite $(\mathrm{NaOCl})$ is the most widely used agent for chemical debridement in endodontic procedures, including regenerative endodontic procedures ${ }^{(6)}$. A well-structured analysis of studies done on regenerative endodontics suggests that $80 \%$ of reported cases used sodium hypochlorite in a concentration of 1 to $6 \%{ }^{(7)}$. The disinfection potential of sodium hypochlorite is concentration dependent and higher concentration translates into greater degree of disinfection but it has been found that higher concentration of sodium hypochlorite leads to decreased survival of stem cells due to denaturation of growth factor ${ }^{(8-10)}$.

Environmental concerns have led researchers to turn to the nature, searching for more biocompatible materials and solutions that will be friendly to environment, as chitin and chitosan. Chitosan presents different biological properties such as; biocompatibility, noncarcinogenic, anti-inflammatory and promotion of cell adhesion, proliferation, and differentiation which are important for regenerative procedure ${ }^{(11)}$. Moreover, several studies demonstrated antimicrobial activity and chelation properties of chitosan which are important for being an irrigating solution ${ }^{(12-17)}$. Due to the previous favorable properties, chitosan and its derivatives have been used to produce a large number of different matrices for tissue engineering applications ${ }^{(18)}$.

After canal disinfection with copious irrigation, it is recommended that the canal be dried with paper points and an intracanal medicament be placed. The most widely used intracanal medicament used in regenerative endodontic procedures is the mixture of ciprofloxacin, metronidazole, and minocycline, to form triple antibiotic paste (TAP). This combination has been shown to be highly efficacious against bacteria commonly found in infected root canal systems in both in vitro ${ }^{(19)}$ and in vivo studies ${ }^{(3,}$ 20-23). However, other intracanal medicaments have been used including $\mathrm{Ca}(\mathrm{OH})_{2}$, the combination of metronidazole and ciprofloxacin (double antibiotic paste-DAP) and the combination of metronidazole, ciprofloxacin, and cefaclor (modified triple antibiotic paste) ${ }^{(24-26)}$.

In several regenerative endodontic or revascularization case reports, immature permanent human teeth with a clinical diagnosis of pulpal necrosis are disinfected, and bleeding is evoked via over instrumentation ${ }^{(3,21,27)}$. The provoked bleeding step acts to deliver stem cells from the periapical tissues such as stem cells from apical papilla (SCAP) to the canal system, as well as providing a fibrin clot that can act as a scaffold to support cellular proliferation, and can provide growth factors present in platelets ${ }^{(27,28)}$. The induction of intracanal bleeding in animal studies has been shown to improve the outcome of regenerative endodontic therapy not only radiographically, but with histologic evaluation too ${ }^{(29)}$. After formation of a blood clot, the orifice of the canal is sealed with MTA, a biocompatible sealing material, which allows the regeneration of new tissue adjacent to it 
followed by permeant coronal restoration ${ }^{(30)}$. Thus the purpose of this study was to evaluate the response of immature permanent teeth with necrotic pulp and apical periodontitis to two revascularization protocols.

\section{MATERIALS AND METHODS}

Approval for this study was obtained from the research ethics committee in the Faculty of Dental Medicine for Girls Al-Azhar University. Twenty upper central incisors with incompletely formed roots from young patients ages (7-18) years old were selected. Informed consent was signed by the guardian after explanation of the treatment protocols and the expected outcomes or alternative management. Patients were divided into two groups (10 roots each). Group I (10 teeth): disinfected using $1.5 \% \mathrm{NaOCl}$ for irrigation and triple antibiotic paste mixed with propylene glycol as a vehicle and revascularization using blood clot. Group II (10 teeth): disinfected using $2 \%$ Chitosan $^{\odot}$ for irrigation and triple antibiotic paste mixed with $2 \%$ Chitosan as a vehicle and revascularization using blood clot.

Treatment protocols: Treatment decision was made based on detailed analysis of clinical and intra-oral radiographic examination. The first appointment; under strict aseptic conditions (rubber dam application), root canal treatment was performed. A working length radiograph was taken approximately $2 \mathrm{~mm}$ shorter than the apex using a suitable size file (according to the canal diameter).The canals were irrigated according to the assigned protocol for each group using side perforated irrigating needle \# 27 . No mechanical instrumentation was performed. A layer of a bonding agent was applied on the walls of the pulp chamber prior to antibiotic paste application in order to minimize crown staining ${ }^{(22)}$. The canals were then dried with sterile paper points and disinfected with

(C) Sigma Co. Egypt

*Egyptian INT. pharmaceutical industries co.

** Sanofi-aventis Egypt s.a.e.

*** Pharco B. INT. Alex. a mixture of antibiotic paste ciprofloxacin* (250 $\mathrm{mg})$, metronidazole ${ }^{* *}(500 \mathrm{mg})$, and cefaclor ${ }^{* * *}(125$ $\mathrm{mg}$ ) mixed with macrogol ointment and propylene glycol (MP) as a vehicle in group I and 2\% Chitosan in group II. The antibiotic paste was inserted into the canals using hand plugger and ensure that it remains below CEJ (minimize crown staining). The access cavities were sealed with a cotton pellet and intermediate restorative material for four weeks ${ }^{(10,31)}$.

The patients were scheduled for a second visit after four weeks. Local anesthetic without a vasoconstrictor was administered as recommended by $\mathrm{AAE}^{(10)}$. After isolation with a rubber dam, the access cavity was reopened, the canals were irrigated with $10 \mathrm{ml}$ saline to remove the triple antibiotic paste. The canals were dried with sterile paper points. K-file \# 30 was introduced into the canals through the apical foramen to provoke bleeding from the periapical tissue into the canals up to the CEJ, stop bleeding a level that allows for 3-4 mm of restorative material. The patients were left for about 5 minutes in order to form a blood clot. A preparation of white mineral trioxide aggregate (MTA) was gently placed over the blood clot. The access cavity was double sealed with a bonded resin restoration (glass ionomer then composite restoration).

Clinical and radiographic evaluation was performed in 3 follow up periods (3, 6 and 12 months). Clinical evaluation was made to assess presence or absence of; Pulp sensitivity, pain with palpation or percussion, sinus tract and Soft tissue swelling. Radiographic evaluation using indirect radiographic system (DBS Win software, Vista Scan System) was applied for assessment of increased root length, increased root thickness, decrease in apical diameter and resolution of apical radiolucency (Linear measurements, diameter of periapical lesion and bone density analysis). 


\section{STATISTICAL ANALYSIS}

Data were collected, coded, tabulated and statistically analyzed using Social Science (IBM SPSS) version 20. The quantitative data were presented as mean values, standard deviations and ranges and percentages of changes. Regarding the quantitative data with parametric distribution, the comparison between two independent groups was done by using Independent t-test. The confidence interval was set to $95 \%$ and the P-value was considered significant as the following: $\boldsymbol{P}>0.05$ : Non significant, $\boldsymbol{P} \leq 0.05$ : Significant, $\boldsymbol{P}<0.01$ : Highly significant.

\section{RESULTS}

\section{Clinical evaluation:}

In the present study clinical findings regarding pain with palpation or percussion, presence or absence of sinus tract and soft tissue swelling, all patients of both groups (I, II) were asymptomatic during the entire follow up evaluation periods ( 3,6 and 12 months). Another clinical finding that has been reported at 12 months follow-up evaluation period is a positive pulp response to hot sensitivity test.

\section{Radiographic evaluation:}

Results of both groups (I, II) showed an increase in root length, thickness, decrease in apical diameter and resolution of periapical radiolucency with a significant difference $(P \leq 0.05)$ over the three follow-up evaluation periods $(3,6,12$ months) compared to the preoperative radiographs.

Regarding the results of percentage increase in root length, the results showed insignificant difference $(P>0.05)$ between the experimental groups (I, II) over the three follow-up evaluation periods (3, 6, 12 months) Table 1 .

The results of percentage increase in root thickness showed significant difference $(P \leq 0.05)$ between the experimental groups (I, II) in subgroup A (3 months). On the other hand, the results were statistically insignificant $(\mathrm{P}>0.05)$ in subgroups $\mathrm{B}$ and $\mathrm{C}$ (6 and 12 months) follow-up evaluation periods (Figure 1).

Regarding the results of percentage decrease in apical diameter, the results were statistically significant $(\mathrm{P} \leq 0.05)$ over the three follow-up evaluation periods (3, 6, 12 months) Table 2 .

Table (1) Mean value and standard deviation (SD) of increase in root length ( $\mathrm{mm})$ and the percentage increase in root length for groups (I, II).

\begin{tabular}{|c|c|c|c|c|c|c|}
\hline \multirow{2}{*}{\multicolumn{2}{|c|}{ Root length }} & \multirow{3}{*}{$\begin{array}{l}\text { Preoperative } \\
14.07 \pm 1.28\end{array}$} & \multirow{3}{*}{$\begin{array}{c}\text { Subgroup A } \\
\text { 3 months } \\
14.95 \pm 1.53^{*}\end{array}$} & \multirow{3}{*}{$\begin{array}{c}\text { Subgroup B } \\
\text { 6 months } \\
15.25 \pm 1.62^{*}\end{array}$} & \multirow{3}{*}{$\begin{array}{c}\text { Subgroup C } \\
\mathbf{1 2} \text { months } \\
15.57 \pm 1.56^{*} \\
\end{array}$} & \multirow{4}{*}{$\begin{array}{c}P \text {-value } \\
<0.001 \\
\text { HS }\end{array}$} \\
\hline & & & & & & \\
\hline \multirow{3}{*}{ Group I } & Mean \pm SD & & & & & \\
\hline & Range & $12.42-15.52$ & $13.18-17.42$ & $13.37-17.72$ & $13.45-17.83$ & \\
\hline & $\%$ change & & $6.25 \%$ & $8.39 \%$ & $10.66 \%$ & $\begin{array}{c}<0.001 \\
\text { HS }\end{array}$ \\
\hline \multirow{3}{*}{ Group II } & Mean \pm SD & $15.15 \pm 1.08$ & $16.04 \pm 1.21 *$ & $16.22 \pm 1.12^{*}$ & $16.95 \pm 1.31 *$ & \multirow{2}{*}{$\begin{array}{c}<0.001 \\
\text { HS }\end{array}$} \\
\hline & Range & $13.42-16.23$ & $13.82-17$ & $14.28-17.5$ & $14.73-17.97$ & \\
\hline & $\%$ change & & $5.87 \%$ & $7.06 \%$ & $11.88 \%$ & $\begin{array}{c}<0.001 \\
\text { HS }\end{array}$ \\
\hline \multirow{3}{*}{$\begin{array}{l}\text { Independent } \\
\text { t-test }\end{array}$} & $\mathrm{T}$ & -2.033 & -1.755 & -1.560 & -2.137 & \\
\hline & p-value & 0.057 & 0.096 & 0.136 & 0.047 & \\
\hline & Sig. & NS & NS & NS & $S$ & \\
\hline \multicolumn{2}{|c|}{ P-value of $\%$ change } & -- & 0.892 NS & 0.684 NS & 0.657 NS & \\
\hline
\end{tabular}

NS: Non significant; S: Significant; HS: Highly significant; NA: Not applicable. ${ }^{*} P \leq 0.05$ versus preoperative 
Healing of the periapical radiolucency was recorded in different parameters, the results showed decrease in linear measurements and diameter of the periapical lesion as well as increase in bone density through the follow-up evaluation periods (3, 6, 12 months), with no statistical significant difference $(P>0.05)$ between the two experimental groups (Figure 2).

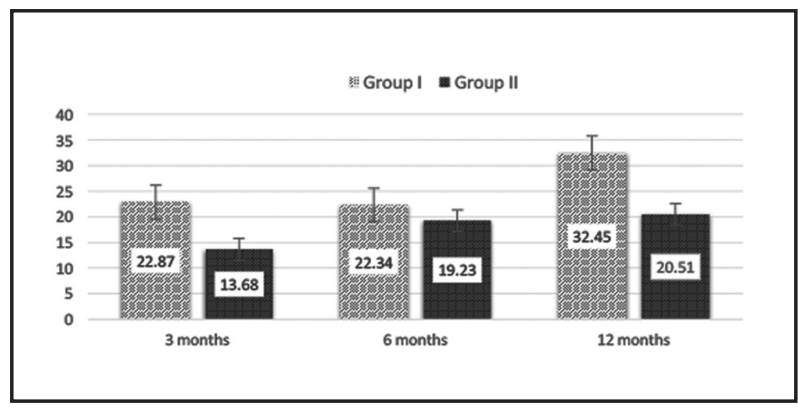

Fig. (1) Histogram showing percentage increase in root thickness (\%) for groups I, II ( $\mathrm{NaOCl}$ and Chitosan) compared to preoperative.

Table (2): Mean value and standard deviation $(S D)$ of apical diameter $(\mathrm{mm})$ and the percentage decrease of apical diameter for groups $(I, I I)$.

\begin{tabular}{|c|c|c|c|c|c|c|}
\hline \multirow{2}{*}{\multicolumn{2}{|c|}{ Apical diameter }} & \multirow{3}{*}{$\begin{array}{c}\text { Preoperative } \\
1.78 \pm 0.48\end{array}$} & \multirow{3}{*}{$\begin{array}{c}\text { Subgroup A } \\
\text { 3 months } \\
1.17 \pm 0.49 *\end{array}$} & \multirow{3}{*}{$\begin{array}{c}\text { Subgroup B } \\
\text { 6 months } \\
1.11 \pm 0.52 *\end{array}$} & \multirow{3}{*}{$\begin{array}{c}\text { Subgroup C } \\
12 \text { months } \\
1 \pm 0.42^{*}\end{array}$} & \multirow{3}{*}{ P-value } \\
\hline & & & & & & \\
\hline \multirow{3}{*}{ Group I } & Mean \pm SD & & & & & \\
\hline & Range & $1.17-2.3$ & $0.63-1.87$ & $0.43-1.8$ & $0.43-1.57$ & $<0.001$ \\
\hline & $\%$ change & & $-34.27 \%$ & $-37.64 \%$ & $-43.82 \%$ & $<0.001$ \\
\hline \multirow{3}{*}{ Group II } & Mean \pm SD & $2.31 \pm 0.52$ & $1.97 \pm 0.62 *$ & $1.85 \pm 0.61 *$ & $1.27 \pm 0.25^{*}$ & \multirow{2}{*}{$<0.001$} \\
\hline & Range & $1.83-3.07$ & $1.33-2.87$ & $1.3-2.77$ & $0.93-1.53$ & \\
\hline & $\%$ change & & $-14.72 \%$ & $-19.91 \%$ & $-45.02 \%$ & $<0.001$ \\
\hline \multirow{3}{*}{$\begin{array}{l}\text { Independent } \\
\text { t-test }\end{array}$} & $\mathrm{t}$ & -2.357 & -3.198 & -2.919 & -1.716 & \\
\hline & p-value & 0.030 & 0.005 & 0.009 & 0.103 & \\
\hline & Sig. & $\mathbf{S}$ & HS & HS & NS & \\
\hline \multicolumn{2}{|c|}{ P-value of $\%$ change } & -- & 0.002 HS & 0.008 HS & 0.000 HS & \\
\hline
\end{tabular}

NS: Non significant; S: Significant; HS: Highly significant; NA: Not applicable. $* P \leq 0.05$ versus preoperative.

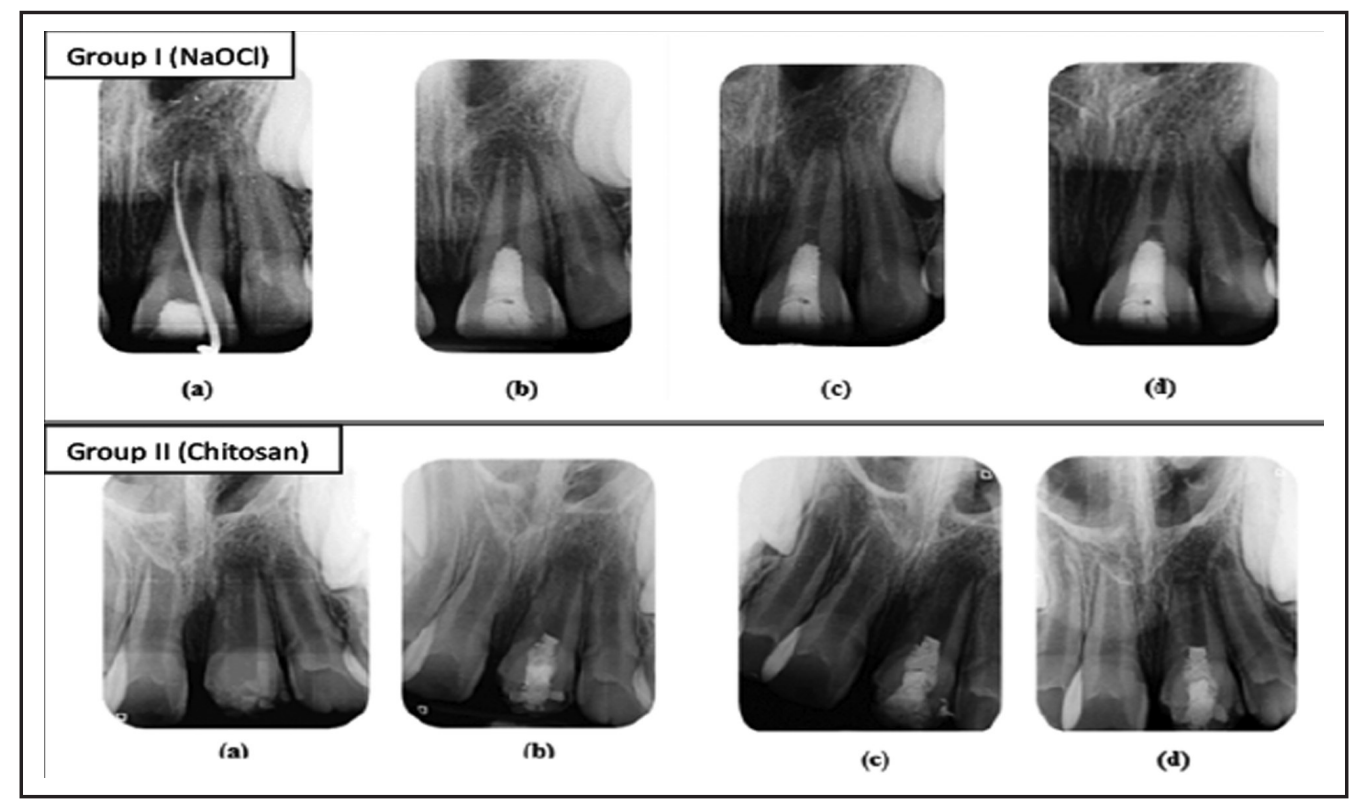

Fig. (2) Representative radiographs of upper left central incisor for group I ( $\mathrm{NaOCl}$ ) and group II (Chitosan) showing improvement in root length, root thickness, apical diameter and periapical radiolucency after three months (b), six months (c) and twelve months (d) compared to the preoperative radiograph (a). 


\section{DISCUSSION}

A growing body of evidence suggests that revascularization endodontic treatment might be possible after pulpal necrosis, even for apical periodontitis in immature teeth with open apices. Blood clot mediated treatment has demonstrated radiographic signs of continued root development with periapical healing ${ }^{(32)}$. Therefore, this study was conducted to evaluate the response of immature permanent teeth with necrotic pulp and apical periodontitis to two revascularization protocols. The selected age of the patients was ranging from 7 to 18 years, as young children have a greater healing capacity with more stem cell regenerative potential $^{(24)}$.

In the present study clinical findings regarding positive pulp response to hot sensitivity test that has been reported at 12 months follow-up evaluation period is corroborated with other studies $(3,30,33,34)$. Although a positive response to a pulp test is not conclusive for the regeneration of pulp tissue in the canal space, it is one of the requirements for showing regeneration. It is important to note that the lack of a pulp response in teeth that underwent REPs does not necessarily indicate a lack of vitality. Several case studies that did not report a positive response to pulp testing showed radiographic evidence of continued root development, indicating the presence of vital tissue in the canal space $20,21,26,35,36)$.

Regarding increase in the root length, radiographic findings showed no statistical significant difference between the two experimental groups. However, there was a borderline difference between group I $(\mathrm{NaOCl})$ and group II (Chitosan), where Chitosan produced higher percentage increase in the root length compared to $\mathrm{NaOCl}$ after 12 months. Moreover, the radiographic thickening of radicular dentin walls showed insignificant differences between the experimental groups after 6 and 12 months. This findings is probably explained by the minimum toxicity of Chitosan and the consequent stimulation of cell adhesion, proliferation, and differentiation, a property previously demonstrated by others ${ }^{(11,37)}$.
The recorded radiographic results of decrease in apical diameter, showed a statistical significant difference in both groups over the three follow-up evaluation periods (3, 6, 12 months). At 3 and 6 months evaluation periods, group $\mathrm{I}(\mathrm{NaOCl})$ showed more percentage decrease in the apical diameter compared to group II (Chitosan), whereas at 12 months follow-up evaluation period, group II (Chitosan) showed more percentage decrease in the apical diameter compared to group $\mathrm{I}(\mathrm{NaOCl})$. These findings may support the hypothesis that Chitosan may give a promising results at long term follow-up period. As $2 \%$ Chitosan assume relatively high viscosity which showed some difficulties in removal from the root canal walls after being used as a carrier for the antibiotic past. Accordingly the advantage of slow and controlled drug release may continue even after removal of the antibiotic paste ${ }^{(38,39)}$.

Regarding the healing of the periapical radiolucency which was recorded in different parameters, the results showed decrease in linear measurements and diameter of the periapical lesion as well as increase in bone density through the follow-up evaluation periods, with no statistical significant difference between the two experimental groups. This finding probably due to proper disinfection of the root canal with irrigant solutions and intracanal medicament, in addition to proper coronal seal with MTA which provide bacteria-free environment ${ }^{(40)}$.

\section{CONCLUSION}

Within the limitations of this study the following could be concluded:

1. Using $2 \%$ Chitosan as an irrigant and vehicle for triple antibiotic paste was at par with $1.5 \%$ $\mathrm{NaOCl}$ irrigating solution and propylene glycol as a vehicle in the revascularization outcome of immature teeth with necrotic pulp and apical periodontitis.

2. Chitosan is a promising natural biomaterial might be used as a feasible alternative to $\mathrm{NaOCl}$ in revascularization protocol using blood clot. 


\section{REFERENCES}

1. Andreasen JO, Farik B, Munksgaard EC. Long-term calcium hydroxide as a root canal dressing may increase risk of root fracture. Dent Traumatol 2002; 18:134-7.

2. Hargreaves K, Law A. Regenerative endodontics. In: Hargreaves K, Cohen S, eds. Pathways of the pulp. St Louis: Mosby Elsevier; 2011:602-19.

3. Banchs F, Trope M. Revascularization of immature permanent teeth with apical periodontitis: new treatment protocol. J Endod 2004; 30:196-200.

4. Fouad AF. The microbial challenge to pulp regeneration. Adv Dent Res 2011; 23,285-9.

5. Law A. Considerations for regeneration procedures. J Endod 2013; 39:S44-56.

6. Diogenes A, Henry MA, Teixeira FB, \& Hargreaves KM. An update on clinical regenerative endodontics. Endod Topics 2013; 28:2-23.

7. Kontakiotis EG, Filippatos CG, Tzanetakis GN, Agrafioti A. "Regenerative Endodontic Therapy: A data analysis of clinical protocols. J Endod 2015; 41:146-54.

8. Martin DE, De Almeida JF, Henry MA, Khaing ZZ, Schmidt CE, Teixeira FB, et al. Concentration-dependent Effect of Sodium Hypochlorite eon Stem Cells of Apical Papilla Survival and Differentiation. J Endod 2014; 40:51-5.

9. Park M, Pang NS, Jung IY. Effect of dentin treatment on proliferation and differentiation of human dental pulp stem cells. Res Dent Endod 2015:1-9.

10. Glossary of Endodontic Terms. Chicago: American Association of Endodontists, 2016.

11. Shrestha S, Torneck CD, Kishen A. Dentin conditioning with bioactive molecule releasing nanoparticle system enhances adherence, viability, and differentiation of stem cells from apical papilla. J Endod 2016; 42: 717-23.

12. Ballal NV, Kundabala M, Bhat K, Acharya S, Ballal M, Kumar R, et al. Susceptibility of Candida albicans and Enterococcus faecalis to Chitosan, Chlorhexidine gluconate and their combination in vitro. Aust Endod J 2009; 35:29-33.

13. Kong M, Chen XG, Xing K, Park HJ. Antimicrobial properties of chitosan and mode of action: A state of the art review. Int J Food Microbiol 2010; 144: 51-63.

14. Fawzy MI. Scanning Electron microscopic evaluation of the effectiveness of Chitosan solution in smear layer removal. Egy Dental J 2011; 57:419-24.
15. Campos PI, La Fuenteha J, Tenorio RF, Acosta TL. Biocompatible antimicrobial irrigants and nanoparticlessealers for endodontics. Entreciencias 2013; 1:9-28.

16. Mohamed MA, Khalefa MM, Fawzy MI. Evaluation of irrigation with chitosan (Biopolymer) on smear layer removal covering intraradicular dentin (SEM study). Master thesis in endodontics, Faculty of Dental Medicine for Girls, Al-Azhar University 2014.

17. Yadav P, Chaudhary S, Saxena RK, Talwar S, Yadav S. Evaluation of Antimicrobial and antifungal efficacy of chitosan as endodontic irrigant against enterococcus faecalis and candida albicans biofilm formed on tooth substrate. J Clin Exp Dent 2017; 9: e361-7.

18. Kmiec M, Pighinelli L, Tedesco MF, Silva MM, Reis V. Chitosan-properties and applications in dentistry. Adv Tissue Eng Regen Med 2017; 2:00035-41.

19. Hoshino E, Kurihara-Aando N, Sato I, Uematsu H, Sato M, Kota K, et al. In-vitro antibacterial susceptibility of bacteria taken from infected root dentin to a mixture of ciprofloxacin, metronidazole and minocycline. Int Endod J 1996; 29:125-30.

20. Reynolds K, Johnson JD, Cohenca N.Pulp revascularization of necrotic bilateral bicuspids using a modified novel technique to eliminate potential coronal discoloration: a case report. Int Endod J 2009; 42:84-92

21. Jung I, Lee S, Hargreaves K. Biologically based treatment of immature permanent teeth with pulpal necrosis: a case series. J Endod. 2008; 34:876-87.

22. Kim JH, Kim Y, Shin SJ, Park JW, Jung IY. Tooth discoloration of immature permanent incisor associated with triple antibiotic therapy: a case report. J Endod 2010; 36:1086-91.

23. Windley W III, Teixeira F, Levin L, Sigurdsson A, Trope M. Disinfection of immature teeth with a triple antibiotic paste. J Endod 2005; 31:439-43.

24. Chueh LH, Ho YC, Kuo TC, Lai WH, Chen YHM, Chiang CP. Regenerative endodontic treatment for necrotic immature permanent teeth. J Endod 2009; 35: 160-4.

25. Shah N, Logani A, Bhaskar U, Aggarwal V. Efficacy of revascularization to induce apexification/apexogensis in infected, non-vital, immature teeth: a pilot clinical study. J Endod 2008; 34:919-25.

26. Thibodeau B, Trope M. Pulp revascularization of a necrotic infected immature permanent tooth: case report and review of the literature. Pediatr Dent 2007; 29: 47-50. 
27. Lovelace T, Henry M, Hargreaves K. Evaluation of clinically delivered SCAP cells in regenerative endodontic procedures. J Endod. 2010; 36:554.

28. Nosrat A, Homayounfar N, Oloomi K. Drawbacks and unfavorable outcomes of regenerative endodontic treatments of necrotic immature teeth: a literature review and report of a case. J Endod 2012; 38: 1428-34.

29. Thibodeau B, Teixeira F, Yamauchi M, Caplan DJ, Trope M. Pulp revascularization of immature dog teeth with apical periodontitis. J Endod 2007; 33:680-9.

30. Petrino JA, Boda KK, Shambarger S. Challenges in regenerative endodontics: a case series. J Endod 2010; 36: 536-41.

31. Kim DS, Park HJ, Yeom JH, Seo JS, Ryu GJ, Ki-Ho Park KH, et al. Long-term follow-ups of revascularized immature necrotic teeth: three case reports. Int J Oral Sci 2012; 4:109-13.

32. Torabinejad M, Milan M, Shabahang S. Histologic examination of teeth with necrotic pulps and periapical lesions treated with 2 scaffolds: an animal investigation. $\mathbf{J}$ Endod 2015; 41:846-52.

33. Torabinejad M, Turman M. Revitalization of tooth with necrotic pulp and open apex by using platelet-rich plasma: a case report. J Endod 2011; 37:265-8.
34. McCabe P. Revascularization of an immature tooth with apical periodontitis using a single visit protocol: a case report. Int Endodo J 2014; 47: 484-97.

35. Chueh LH, Huang GTJ. Immature teeth with periapical periodontitis or abscess undergoing apexogenesis: a paradigm shift. J Endod 2006; 32:1205-13.

36. Thomson A, Kahler B. Regenerative endodontics biologically-based treatment for immature permanent teeth: a case report and review of the literature. Aust Dent J 2010; 55:446-52.

37. Howling GI, Dettmar PW, Goddard PA, Hampson FC, Dornish M, Wood EJ. The effect of chitin and chitosan on the proliferation of human skin fibroblasts and keratinocytes in vitro. Biomaterials 2001; 22: 2959-66.

38. Elsakaa SE, Elnaghy AM. Antibacterial activity of calcium hydroxide combined with chitosan solutions and the outcomes on the bond strength of RealSeal sealer to radicular dentin. J Biomedical Res 2012; 26: 193-9.

39. Grover C, Shetty N. Evaluation of calcium ion release and change in $\mathrm{pH}$ on combining calcium hydroxide with different vehicles. Cont Clin Dent 2014; 5:434-9.

40. Torabinejad M, Hong CU, McDonald F, Pitt Ford TR. Physical and chemical properties of a new root-end filling material. J Endod 1995; 21: 349-53. 